\title{
Micro-environment of olive ridley turtle nests deposited during an aggregated nesting event
}

\author{
S. Clusella Trullas \& F. V. Paladino \\ Biology Department, Indiana Purdue University at Fort Wayne, Fort Wayne, IN, USA \\ Correspondence Susana Clusella Trullas, Centre for Invasion Biology, Department of Botany and \\ Zoology, University of Stellenbosch, Private Bag X1, Matieland 7602, South Africa.
}

\begin{abstract}
The hatching success of nests deposited by olive ridley turtles Lepidochelys olivacea during aggregated nesting events ('arribada') is typically low and the underlying mechanisms are not clear. In this study, temperature, oxygen and carbon dioxide partial pressures $\left(\mathrm{PO}_{2}\right.$ and $\left.\mathrm{PCO}_{2}\right)$ of in situ nests as well as nests relocated into a hatchery with clean sand were monitored throughout incubation. Hatching success of hatchery nests was significantly higher than in situ nests (83.1 vs. 21.6\%) and mainly resulted from higher mortality of early-stage embryos. During the first half of incubation, temperature and $\mathrm{PCO}_{2}$ were higher (by $0.6^{\circ} \mathrm{C}$ and $0.7 \mathrm{kPa}$, respectively) and $\mathrm{PO}_{2}$ was lower (by $1.1 \mathrm{kPa}$ ) within in situ relative to hatchery nests. Because embryo metabolism does not interfere significantly with nest gas contents during the first half of incubation, these results suggest that the greater content of organic matter and/or microorganisms in the sand surrounding in situ nests had an effect on nest gas contents. As $\mathrm{PO}_{2}$ and $\mathrm{PCO}_{2}$ differences were relatively small, microbial activity (such as fungal and bacterial infection) may have caused the early embryo mortality found in situ. Moreover, our results suggest that during the second half of incubation, neither $\mathrm{PO}_{2}$ nor $\mathrm{PCO}_{2}$ reached threshold levels that resulted in the death of embryos or hatchlings. Overall, this study showed a clear benefit of using clean sand to increase hatchling production in arribada beaches and highlights the importance of further investigating the relationship between nest micro-

environment, sand microbial activity and embryo development under natural conditions during these unique nesting events.
\end{abstract}

Keywords: marine reptile; population dynamics; sand quality; conservation; solitary nesting; respiratory metabolism

\section{Introduction}

The endangered olive ridley turtle Lepidochelys olivacea is characterized by two different types of reproductive strategies: solitary and aggregated nesting (Eckrich \& Owens, 1995). The latter, also known as an 'arribada', consists of hundreds of females nesting simultaneously on a single beach over a period of several days (Plotkin et al., 1997). Nancite beach is renowned for its large arribadas and may contribute significantly to the olive ridley eastern Tropical Pacific population (Pritchard \& Plotkin, 1995). However, the number of arribadas per season as well as the number of nests per arribada in Nancite have declined significantly over the past 10-15 years (Valverde, Cornelius \& Mo, 1998). In addition, the hatching success of egg-clutches deposited during arribadas at Nancite is very low ( 4.5\%; Mo, Salas \& Caballero, 1990; Cornelius et al., 1991), and may contribute to a population decline if coupled with high mortality rates of juveniles and/or adults (Crouse, 1999; Spotila et al., 2000). Valverde et al. (1998) proposed that the metabolic activity associated with the high density of developing embryos and the microbial decomposition of organic matter accumulated from prior unsuccessful nests may lower the oxygen (and raise carbon dioxide) content in nests and affect 
normal development of embryos. However, the mechanisms underlying this hypothesis have not been tested directly.

The micro-environment of incubating eggs in sea turtle nests is affected by temporally and spatially variable biotic (e.g. microorganisms, predators) and abiotic (e.g. sand characteristics, gas content, humidity, temperature) factors that may interact with each other in a non-linear fashion (Packard \& Packard, 1988; Ackerman, 1997). Nest micro-environment (i.e. temperature, gas partial pressures and moisture) may affect the growth rate (e.g. Ackerman, 1981), size (e.g. Packard \& Packard, 1988), sex of embryos (e.g. Standora \& Spotila, 1985), hatching success (e.g. Mortimer, 1990) and incubation duration (e.g. Ackerman, 1981) (see Packard \& Packard, 1988 for a review). For example, temperature and water content can affect nutrient mobilization of embryos as well as the size and energy reserves of hatchlings (Booth \& Astill, 2001; Hewavisenthi \& Parmenter, 2001). Also, inadequate gas exchange in the nest may prolong egg incubation, jeopardize normal embryo development and increase mortality (Ackerman, 1981).

Studies on sea turtle nest environment typically focus on a single parameter. For example, nest temperature has been monitored throughout incubation of eggs for several species and populations due to its role in embryo sex determination (e.g. Morreale et al., 1982; Broderick, Godley \& Hays, 2001; Hewavisenthi \& Parmenter, 2002) but relatively little is known about the temporal variation of gas contents within incubating nests (but see Ackerman, 1977; Maloney et al., 1990; Wallace et al., 2004). In order to gain an insight into the underlying mechanisms causing greater mortality of hatchlings, several factors should be monitored simultaneously. As such, the simultaneous measurement of gases and temperature within nest chambers may provide valuable insights into hypoxic and hypercapnic effects on incubation period, embryo mortality and hatching success of eggclutches.

The aims of this study were twofold. First, we aimed to measure temporal variation in temperature and gas contents (both oxygen and carbon dioxide) throughout the incubation period of olive ridley egg clutches, coupled with estimates of hatching success. Second, we aimed to compare incubation temperature, oxygen and carbon dioxide partial pressures $\left(\mathrm{PO}_{2}\right.$ and $\left.\mathrm{PCO}_{2}\right)$ and hatching success of in situ nests deposited during an arribada with nests relocated to a hatchery containing clean sand. We predict that due to the lower egg residual content (thereby, lower microbial biota) in the hatchery sand, $\mathrm{PO}_{2}$ should be higher and $\mathrm{PCO}_{2}$ should be lower than in natural (in situ) nests. We also expect that nest temperature will be higher under in situ conditions due to latent heat released by the decomposition of organic matter. These differences should be particularly noticeable during the first half of incubation when the metabolism of embryos is not interfering greatly with nest gas contents.

\section{Materials and methods}

\section{Study site}

The study was conducted at Nancite beach $\left(10^{\circ} 45^{\prime} \mathrm{N}, 85^{\circ} 40^{\prime} \mathrm{W}\right)$ located within Santa Rosa National Park on the northern Pacific coast of Costa Rica. The beach length was $c .1 \mathrm{~km}$ and its width varied from 5 to $30 \mathrm{~m}$ (most sections were $>20 \mathrm{~m}$ from high tide to vegetation line). Fieldwork took place during the peak nesting season of 1999 (August-October, rainy season) when the largest arribadas occur monthly (Hughes \& Richard, 1974; Valverde et al., 1998). All study nests (hatchery and in situ) were deposited during September's arribada, which lasted six nights. The size of this event was estimated at $\sim 20000$ turtles and represented the first large arribada of the season.

\section{Hatchery setting}

The hatchery was located in the upper section of the beach ( $5 \mathrm{~m}$ seaward of the vegetation line) in an attempt to prevent flooding by high tides or the adjacent estuary. Hatchery nests were relocated into 
a $6 \times 5$ matrix at $1 \mathrm{~m}$ intervals (total of 30 nests, hatchery area: $90 \mathrm{~m}^{2}$ ) and did not include any vegetation cover. The original sand (which contained large quantities of egg residuals such as shells and rotten eggs) was replaced to a depth of one meter by sand obtained from the area adjacent to the high tide line. This sand was considered 'clean' because rotten eggs and organic matter from previous nestings had been removed by tidal activity. Also, sand was carefully sieved through a coarse-grain mesh $\left(5 \mathrm{~mm}^{2}\right)$ before placement in the hatchery to remove any remaining eggshells. The entire hatchery area was protected by placing a $1.2 \mathrm{~m}$ high wire mesh $(1 \times 1 \mathrm{~cm}$ mesh size $)$ fencing with $50 \mathrm{~cm}$ buried below the sand surface. Thirty clutches were collected from ovipositing females by introducing a plastic bag inside the nest cavity as soon as the female completed the construction of the nest chamber, and thus avoiding the contact of the eggs with beach sand. Egg-clutches were buried in the hatchery (at average depth for natural nests, bottom of chamber at $40 \mathrm{~cm}$ ) immediately after collection to avoid embryo death (following Wyneken et al., 1988). Nest chambers were dug by hand and replicated the size and shape of natural nests. Eggs were counted and placed in chambers using sterile latex gloves and the sand placed above each clutch was compacted to replicate the female's nesting behavior. By day 45 of the incubation period, wire mesh cages were placed above each nest to contain and count emerging hatchlings.

\section{Nest environment and hatching success}

A temperature and gas sampling device was placed at random in 20 out of 30 hatchery nests and in 15 out of 20 in situ nests deposited during the arribada. One device was placed at the center of the egg-clutch and consisted of a 24-gauge copper-constantan thermocouple and the tip of $60 \mathrm{~cm}$ of Tygon tubing inserted into a perforated plastic canister. The thermocouple wire and tubing extended to the sand surface where shut-off valves impeded additional gas exchange. The temperature inside the nest was measured using a digital thermocouple meter $\left( \pm 0.1^{\circ} \mathrm{C}\right.$; BAT-12, Physitemp, Clifton, NJ, USA), and readings were made every 3 days at 09:00 h (local time). Air samples ( $20 \mathrm{~mL}$ ) were drawn using plastic syringes every 5 days for the first 30 days of incubation and every 4 days for the last 30 days (or until hatchling emergence from the sand). Before each sample, a $10 \mathrm{~mL}$ dead space air sample was collected and expelled to remove air in the tubing. All samples were collected from 09:00 h onwards and analyzed within $1 \mathrm{~h}$ of sampling using calibrated $\mathrm{CO}_{2}$ and $\mathrm{O}_{2}$ analyzers (AEI Technologies, Model CD-3A and Model S-3A, Pittsburg, PA, USA). Gas samples were injected using a syringe pump (Razel Scientific Instruments Inc., St Albans, UT, USA) through a column containing Drierite to absorb any water vapor before entering the oxygen sensor and all gas percentages were converted to partial pressures using ambient barometric pressure. In situ nests were located in between the high tide line and the vegetation and were selected by choosing three consecutive nesting turtles in each of five sectors ( $200 \mathrm{~m}$ width) that covered the total length of the beach $(1 \mathrm{~km})$. Nests within a single sector were at least $3 \mathrm{~m}$ apart. Nests were opened once females had left the beach and temperature-gas devices were placed at the center of each egg-clutch using the same precautions as for hatchery nests. Each in situ nest was caged with a mesh screen during the entire incubation period.

Shaded ambient temperature at sand surface $\left(T_{\mathrm{a}}\right)$, sand temperature at nest depth $\left(T_{\mathrm{s}}, 35 \mathrm{~cm}\right.$; digital thermocouple reader) and sand moisture tension (Jet-Fill Tensiometer Model 2725, Soil Moisture Equipment Corp., Santa Barbara, CA, USA) were recorded every 3 days at 09:30 $\mathrm{h}$ inside (center of hatchery, all nests located $>0.5 \mathrm{~m}$ from probe) and outside the hatchery ( $5 \mathrm{~m}$ seaward from hatchery). In addition, rainfall was monitored daily by placing a standard rain gauge next to the hatchery's fence. The incubation period was calculated as the number of days between the day of egg deposition and the day the first hatchlings emerged from the sand. Three days after the emergence of the first hatchlings, nests were excavated and unhatched eggs were opened to determine the stage of embryonic development. We distinguished five categories within each nest (following Miller, 1985): (1) live hatchlings, (2) dead hatchlings [hatchlings (1) and (2) had not emerged at the sand surface], (3) late development embryos (i.e. fully pigmented and formed embryos, with yolk volume <embryo volume), (4) middle development embryos (i.e. presence of pigmentation, yolk volume>embryo volume) and (5) early development embryos (i.e. presence of 
embryonic membranes, blood formations or small unpigmented embryo). In a few instances, eggs (two hatchery and eight in situ eggs) had a decomposed consistency that impeded differentiation between early-stage embryo and infertile. These eggs were excluded from category (5). Despite a general decomposition (smell and shell coloration) of most egg-clutches by the end of incubation, the distinction between embryo categories (3)-(5) was easily made. We defined 'metabolizing embryos' as the sum of all categories, but excluding (5). This distinction was made because categories (1)-(4) should contribute the most to metabolism in the nest (i.e. embryo growth; Packard \& Packard, 1988). Hatching success (\%) was defined as the proportion of hatchlings that hatched out of their eggshell (Miller, 1999) relative to the total number of eggs originally deposited in the nest. Nests that were destroyed by natural causes such as erosion and predation were not included in the analyses.

\section{Data analysis}

Sea turtle embryos are characterized by little growth during the first half of incubation, followed by a period of rapid growth during the second half (Ackerman, 1981; Booth \& Astill, 2001). As embryo metabolism is low during the first half of incubation, differences in nest gas contents during this period could presumably be attributed to microbial activity. Therefore, the gas contents and temperature in hatchery and in situ nests were analyzed for the first and second half of incubation separately. Most analyses were conducted using Statistica (v. 6.0; Statsoft Inc., Tulsa, OK, USA). When assumptions of normality and homogeneity of variance were not satisfied, non-parametric statistics were used (Mann-Whitney $U$-test). Repeated measurements of temperature, $\mathrm{PO}_{2}$ and $\mathrm{PCO}_{2}$ were analyzed with repeated measures ANOVA (PROC MIXED model using a compound symmetry covariance structure, Littell et al., 1996; SAS statistical software, v. 9.0, SAS Institute, USA). Because conditions in temperature, $\mathrm{PO}_{2}$ and $\mathrm{PCO}_{2}$ should be more uniform among hatchery nests compared with in situ nests (i.e. less affected by differing densities of neighboring nests, decomposing organic matter and microorganisms), we assessed the relationships of temperature, $\mathrm{PO}_{2}$ and $\mathrm{PCO}_{2}$ and characteristics of clutches (i.e. clutch size, metabolizing embryos and incubation period) for hatchery nests using Spearman's rank correlation coefficients. Values are expressed as means \pm 1 standard deviation (sd). Percentage data, such as hatching success, were arcsinetransformed before analysis. All analyses were tested for statistical significance at $P<0.05$.

\section{Results}

Despite high rainfall (totaling $1807 \mathrm{~mm}$ of rain in 65 days, Fig. 1), beach and hatchery nests were not submerged under water for long periods as there was good sand drainage. However, a flow of estuarine water towards the ocean, coupled with heavy rains and high tides, caused major erosion of the beach. We estimated that $75 \%$ of the initial beach area washed away, along with thousands of eggs. This erosion caused a $1 \mathrm{~m}$ decline between the original beach height and the new beach surface. As a result, this large erosion was the major factor that caused mortality of eggs deposited during the arribada in the present study and of eggs deposited before this event but that had not reached full term. Study nests were progressively destroyed throughout the second half of the incubation period (i.e. after day 30; total incubation period $\sim 60$ days, see Table 1). Only 14 (10 with temperature and gas devices) out of 30 hatchery nests and four (all with temperature and gas devices) out of 20 in situ nests remained at the end of the study. Sand moisture and sand temperature at nest depth as well as ambient temperature at the sand surface for hatchery and beach sites were similar throughout the study period (Table 2 ).

On average, initial egg-clutches ( 30 hatchery and 20 in situ nests) contained $102 \pm 14.3$ eggs. There was no significant difference between clutch size (i.e. number of eggs) of hatchery and in situ nests (when comparing all initial nests: $U=206.5, P=0.66$, or when comparing nests with temperature and gas devices left after erosion: $U=11.0, P=0.20$ ). Hatching success for hatchery nests (range: $59-99 \%)$ was significantly greater than for in situ nests (3-45\%; Table 1). Also, in situ nests had greater numbers of early-stage embryo deaths than hatchery nests (Table 1 ). 


\section{Temperature}

Nest temperatures decreased during the first half ( 30 days) of the incubation period, with major decreases associated with heavy rainfall events (Fig. 1). Sand temperature at nest depth followed the same trend (Fig. 1). Hatchery nest temperatures during this period were significantly lower than for in situ nests (Location effect, Table 3). Nest temperatures increased during the second half of the incubation period (after day 30), except for a decrease between the 40th and 46th day coinciding with heavy rainfall (day effect, Table 3 ). The average maximum temperature measured in hatchery clutches was $32.8 \pm 1.1^{\circ} \mathrm{C}$ (day 58 , absolute maximum: $35.2^{\circ} \mathrm{C}$ ), occurred on average 3 days before the first emergence of hatchlings at the sand surface and differed from in situ nests and control sand temperature by an average of $0.3-3.6^{\circ} \mathrm{C}$, respectively (Fig. 1). The average minimum temperature in hatchery and in situ nests was $24.0 \pm 0.1$ and $24.2 \pm 0.2^{\circ} \mathrm{C}$, respectively (day 28 , absolute minimum: $23.9^{\circ} \mathrm{C}$ ). For hatchery nests, there were no significant correlations between temperature and nest characteristics (i.e. clutch size, metabolizing embryos and incubation period; Table 4).

\section{Gas partial pressures}

During the first half of the incubation period, $\mathrm{PO}_{2}$ in beach nests was significantly lower than in hatchery nests (Table 3, Fig. 2a). Thereafter, $\mathrm{PO}_{2}$ decreased over the next 20 days (Fig. 2a). For hatchery nests, $\mathrm{PO}_{2}$ started increasing on day 51 when presumably the first hatchlings pipped out of their eggshells, crawled up the nest to emerge at the sand surface by day 60 . In contrast, $\mathrm{PO}_{2}$ of in situ nests remained relatively constant from day 51 onwards. During the first half of incubation there were no significant relationships between $\mathrm{PO}_{2}$ and clutch size, number of metabolizing embryos or incubation period in hatchery nests (Table 4). However, the minimum $\mathrm{PO}_{2}$ for the entire incubation period ( days 51-55, average: $14.6 \pm 1.7 \mathrm{kPa}$, range: $12.6-17.8 \mathrm{kPa}$ ) decreased as the clutch size and number of metabolizing embryos increased (Table 4).

During the first half of incubation, $\mathrm{PCO}_{2}$ for in situ nests was significantly higher than in hatchery nests (Table 3, Fig. 2b). Strong Day and Day $\times$ Location effects (Table 3) indicated that $\mathrm{PCO}_{2}$ in hatchery and in situ nests exhibit a different pattern of variation among days. The average $\mathrm{PCO}_{2}$ increased over the subsequent 20 days, especially in hatchery nests (by 21-fold) compared with in situ nests (sevenfold; Fig. 2b). After day $51, \mathrm{PCO}_{2}$ in hatchery nests remained constant for a few days before decreasing sharply just before and during hatchling emergence. In contrast, $\mathrm{PCO}_{2}$ of in situ nests remained relatively constant for the remainder of incubation. During the first half of incubation, clutch size was positively correlated with maximum $\mathrm{PCO}_{2}$ in hatchery nests ( day 20, average: $0.30 \pm 0.06 \mathrm{kPa}$, range: $0.19-0.40 \mathrm{kPa}$; Table 4). Finally, the number of metabolizing embryos was positively correlated with minimum $\mathrm{PCO}_{2}$ ( day $25,0.15 \pm 0.03,0.10-0.20 \mathrm{kPa}$ ) and with mean $\mathrm{PCO}_{2}(1.99 \pm 0.42,2.58-1.16 \mathrm{kPa})$ from the entire incubation period (Table 4).

\section{Discussion}

Hatching success in the hatchery (83.1\%) was significantly higher than in situ (21.6\%), indicating that the low beach hatching success at Nancite was not due to an intrinsic egg factor such as infertility. Instead, biotic (microbe infestation) and/or abiotic (temperature, gas content) conditions likely affected embryo development. Our results contrast with those of Eckert \& Eckert (1990), who found that the hatching success of in situ leatherback Dermochelys coriacea nests was higher than nests translocated into stable beach zones. In the latter study, the difference was associated with a higher proportion of dead hatchlings in translocated clutches, whereas in Nancite the low hatching success of in situ nests was primarily related to a higher proportion of dead embryos early during incubation (Table 1). Also, the hatching success of in situ and hatchery nests of solitarily nesting olive ridley turtles (average of 33 nests per month) monitored at Playa Cuixmala (Mexico) were not significantly different and averaged $62 \%$ (García, Ceballos \& Adaya, 2003). Therefore, the micro-environmental 
conditions of nests in an arribada beach (i.e. high nest density) may differ greatly from nests deposited solitarily.

The hatching success of in situ nests was higher than that in the same beach during prior nesting seasons (i.e. 4.2\%, Cornelius et al., 1991; 4.8\%, Mo et al., 1990). In addition, very low hatching rates (i.e. 6.7-10.7\%) have been reported for similar arribada beaches (Cornelius et al., 1991). The relatively higher hatching success found in this study can be attributed to two possible reasons. First, due to uncontrollable factors (i.e. high seasonal rains) and considerable loss of in situ nests, hatching success estimates were made for a relatively low sample size by the end of the season. Second, this study was performed early in the nesting season and before build-up of high quantities of fresh organic matter deposited during prior arribadas. It is possible that the hatching success of in situ conditions would decline over the course of the nesting season due to build-up of organic matter over time.

Because of concerns that we may have erroneously failed to reject the null hypothesis as a consequence of the low sample sizes for in situ nests, we determined the likelihood of committing a Type II error when comparing hatchery and in situ hatching success values ( $n_{1}$ and $n_{2}$, respectively) using two statistical approaches. First, a post hoc power analysis revealed that there was $<0.01 \%$ chance of committing this type of error [Effect size (calculated from the means of the two groups and the single largest variance): $d=3.53, n_{1}=14, n_{2}=4, \alpha=0.05, t_{16}=2.12,6$ (power) $=0.99$ ]. Second, after applying a randomization protocol to the hatching success data (resample-without-replacement, two-tail $t$-statistic for 2000 randomized samples), we found that hatchery and in situ hatching success were significantly different (effect size $=2.02, t=7.14, P<0.0001$ ). Therefore, we are confident that the difference in hatching success between hatchery and in situ nests was genuine and not simply a stochastic artifact of small sample sizes.

\section{Temperature}

It is unlikely that the small difference between hatchery and in situ nest temperatures during the first half of incubation (i.e. $0.6 \pm 0.3^{\circ} \mathrm{C}$ ) negatively affected embryo development or hatching success. In reptiles, normal development of embryos is generally possible over a range of several degrees celsius (Packard \& Packard, 1988), while morphological abnormalities or high embryonic mortality may occur outside this range (Packard, Tracy \& Roth, 1977). Despite a relatively large variation in temperature (i.e. $8.9 \pm 0.9^{\circ} \mathrm{C}$ ) throughout the incubation period of hatchery nests, no embryo abnormalities or unusually high mortalities were found. Sea turtle eggs seldom hatch when incubated at constant temperatures $<24$ or $>33^{\circ} \mathrm{C}$ for extended periods of time (Yntema \& Mrosovsky, 1980; Ackerman, 1997). The high hatching success of hatchery nests indicated that the brief exposure of eggs to (or below) $24^{\circ} \mathrm{C}$ ( day 28 of incubation) during heavy rainfall did not have a detrimental effect on embryonic development. However, studies examining thermal tolerance, phenotypic plasticity (i.e. acclimation) and developmental trade-offs during embryo and hatchling ontogeny in this species are required to determine possible fitness consequences in the wild [but see Drake \& Spotila (2002) for critical thermal maxima of L. olivacea hatchlings].

\section{Gas partial pressures}

Ackerman (1981) suggested that an optimal respiratory environment for the development of sea turtle eggs (i.e. appropriate $\mathrm{PO}_{2}$ and $\mathrm{PCO}_{2}$ ) should result in the greatest hatching success. During the first half of incubation, $\mathrm{PO}_{2}$ within in situ nests was lower and $\mathrm{PCO}_{2}$ was higher when compared with hatchery nests. It is unlikely that these differences (i.e. 1.07 and $0.67 \mathrm{kPa}$ for $\mathrm{PO}_{2}$ and $\mathrm{PCO}_{2}$, respectively) severely affected embryonic growth and development. $\mathrm{PO}_{2}$ and $\mathrm{PCO}_{2}$ were within the ranges of respiratory gas contents typically found in nests of other species of sea turtles with normal embryonic development (e.g. Ackerman, 1977). In addition, sea turtle eggs have a high $\mathrm{O}_{2}$ conductance and embryos are characterized by low oxygen consumption rates during the early 
stages of incubation (Ackerman, 1980). However, the possibility of mild hypoxia and/or hypercapnia effects on early embryogenesis cannot be completely discarded. For example, Booth (2000) showed that even a small decrease in $\mathrm{PO}_{2}$ in crocodile Crocodylus porosus mounds resulted in decreased oxygen consumption of embryos of all ages.

During the second half of incubation, $\mathrm{PO}_{2}$ decreased and $\mathrm{PCO}_{2}$ increased within nests due to higher growth rates and increased metabolic activity of embryos exceeding the diffusion capacity of the surrounding sand (Ackerman, 1981; Wallace et al., 2004). These trends were less profound for in situ nests because of the reduced number of viable embryos and hatchlings within these nests. Our results suggest that during the second half of incubation, neither $\mathrm{PO}_{2}$ nor $\mathrm{PCO}_{2}$ reached threshold levels that resulted in the death of embryos or hatchlings (but see Kam, 1993a for potential structural and physiological changes of eggs and embryos in response to hypoxia).

Likewise, Wallace et al. (2004) suggested that hypoxia did not contribute to the low hatching success found in leatherback $D$. coriacea nests, although these authors did not monitor $\mathrm{CO}_{2}$ for possible hypercapnic effects.

There are no data available on gas contents for nests of $L$. olivacea. Therefore, the values of $\mathrm{PO}_{2}$ and $\mathrm{PCO}_{2}$ are compared with those of other sea turtle species. The average maximum $\mathrm{PCO}_{2}(5.7 \mathrm{kPa})$ in our study was greater than that of Caretta caretta ( 3.0 kPa, Maloney et al., 1990) and close to the range of maximum $\mathrm{PCO}_{2}$ found in $D$. coriacea nests (from 1.5 to $5.4 \mathrm{kPa}$; Reynolds, 2000; Ralph et al., 2005) for which Reynolds (2000) reported high emergence success. In Trachemys scripta, Etchberger et al. (1992) showed that high levels of $\mathrm{CO}_{2}(10.1-15.2 \mathrm{kPa})$ increased the incubation period and embryo mortality relative to eggs incubated at $0 \mathrm{kPa}$. However, in the latter study, $\mathrm{PCO}_{2}$ levels were greater than the range of $\mathrm{PCO}_{2}$ found in our study.

The average minimum $\mathrm{PO}_{2}$ in our study nests $(14.6 \mathrm{kPa})$ was also within the range of values reported for nests of other sea turtle species (from 10 to $18.9 \mathrm{kPa}$; see e.g. Ackerman, 1977; Wallace et al., 2004). Embryos of Chelonia mydas and $C$. caretta incubated in containers with conductances of respiratory gases similar to those of nests in beach sand $\left(\mathrm{PO}_{2} \sim 12 \mathrm{kPa}\right.$ and $\mathrm{PCO}_{2} \sim 6.7 \mathrm{kPa}$ just before hatching) had higher growth rates, shorter incubation periods and higher hatching success than embryos in containers with lower conductances (but values of $\mathrm{PO}_{2}$ and $\mathrm{PCO}_{2}$ were not reported for these nests; Ackerman, 1981).

There are very few studies reporting sea turtle embryonic sensitivity to micro-environmental challenges such as hypoxia and hypercapnia. Measurements such as the critical oxygen tension $\left(P_{\mathrm{c}}\right)$ of embryos, defined as the $\mathrm{PO}_{2}$ at which the oxygen consumption of the embryo is first reduced, could give an indication of its hypoxia tolerance. Kam (1993b) found that $P_{\mathrm{c}}$ for $C$. caretta embryos (16.5 kPa on day 22 of incubation) were high compared with those of the Florida red-bellied turtle (Pseudemys nelsoni, 9.9-16.1 kPa from days 12 to 40), indicating that sea turtle embryos had less tolerance to hypoxia, especially during the first half of incubation. The determination of $P_{\mathrm{c}}$ for olive ridley embryos may clarify the potential effects of the reduced respiratory gases found in Nancite beach on embryo development and hatching success.

Respiratory gas exchange between eggs in a nest and the atmosphere is generally limited by physical sand properties (i.e. grain size/type, permeability) that influence the diffusion of gas and by characteristics of the developing clutch (Ackerman, 1997). Similar gas diffusion coefficients for sand surrounding hatchery and in situ nests may be expected as sand characteristics are generally similar for a particular beach and the sand above all egg clutches was equally compacted. However, the lack of egg residuals (i.e. fresh and decomposed) in the hatchery may explain the difference found in gas content during the first half of incubation. The presence of high densities of microorganisms in the sand has been reported for Nancite (six orders of magnitude higher than for an adjacent beach without aggregated nesting; Mo et al., 1990) and other arribada beaches (Acuña et al., 1999). The increase in the amounts of organic matter (as a consequence of aggregated nesting and destruction of nests by other nesting turtles; Cornelius et al., 1991) may increase microbial respiration as well as 
the possibility of bacterial and/or fungal infection of in situ eggs. As shown by Phillott \& Parmenter (2001a), incidental egg mortality in nests may cause fast fungal colonization from an individual egg to adjacent viable eggs. Therefore, the combination of differences in $\mathrm{PO}_{2}, \mathrm{PCO}_{2}$ and temperature during the first half of incubation, coupled with the state of microbial activity of Nancite beach sand, may have interfered with the development of in situ embryos early in incubation. Despite their potential significance, the magnitude of differences in micro-environment $\left(\mathrm{PO}_{2}\right.$ and $\left.\mathrm{PCO}_{2}\right)$ between in situ and hatchery nests was small and thus, we cannot ascertain that the reduction in optimal levels of in situ nests facilitated or further enhanced embryo mortality caused by microbial activity (see Phillott \& Parmenter, 2001b for impairment of egg gas exchange due to fungal growth). These results reiterate the need to determine the susceptibility of olive ridley eggs to microbial infection under different nest gas content scenarios as well as embryo metabolic requirements throughout incubation.

The evolutionary advantage of aggregated as opposed to solitary nesting is puzzling, especially in light of the higher mortality associated with the former. However, by showing a clear benefit of clean sand as a means to increase hatchling production, this study may indicate when an arribada could be advantageous over longer time periods. Although direct evidence of microbial activity is lacking, here, we provide the first complete data on nest environment (temperature and gas exchange) of egg-clutches during an arribada, and thereby provide indirect support for the microbial activity hypothesis in limiting hatching success. Because arribada beaches are often associated with estuaries or river mouths (e.g. Cornelius et al., 1991; Tripathy, Shanker \& Choudhury, 2003), rains and high tides may result in beach erosions. Large erosions such as the one in our study are rare but when erosion events occur, they typically result in replacement and/or cleaning of the beach sand. Therefore, they could provide the necessary medium to ensure high arribada hatching success. The fitness advantage of arribadas occurring immediately after an erosion event may offset the high mortality throughout subsequent nesting events. In conclusion, this study highlights the importance of investigating the complex link between sand microbial activity, nest environment and embryo development in arribada beaches.

\section{Acknowledgments}

We thank Roger Blanco for his support at the Area de Conservación Guancaste, James R. Spotila for instrumentation and Lenin Guadamuz for field assistance at Nancite Research Station. Jack Frazier, John S. Terblanche and two anonymous reviewers provided useful comments on an earlier version of this manuscript. This work was funded by Earthwatch Institute and Indiana-Purdue University at Fort Wayne. Research was approved by Purdue Animal Care and Use Committee (86-213-04 and 86-21304) and conducted under research permit 208-99-OFAU from the Costa Rica Ministerio del Ambiente y Energía.

\section{References}

- Ackerman, R.A. (1977). The respiratory gas exchange of sea turtle nests (Chelonia, Caretta). Respir. Physiol. 31, 19-38.

- Ackerman, R.A. (1980). Physiological and ecological aspects of gas exchange by sea turtle eggs. Am. Zool. 20, 575-583.

- Ackerman, R.A. (1981). Growth and gas exchange of embryonic sea turtles (Chelonia, Caretta). Copeia 1981, 757-765.

- Ackerman, R.A. (1997). The nest environment and the embryonic development of sea turtles. In Biology of sea turtles: 83-106. Lutz, P.L. \& Musick, J.A. (Eds). New York: CRC Press.

- Acuña, M.T., Díaz, G., Bolaños, H., Barquero, C., Sánchez, O., Sánchez, L.M., Mora, G., Chaves, A. \& Campos, E. (1999). Sources of Vibrio mimicus contamination of turtle eggs. Appl. Environ. Microb. 65, 336-338.

- Booth, D.T. (2000). The effect of hypoxia on oxygen consumption of embryonic estuarine crocodiles (Crocodylus porosus). J. Herpetol. 34, 478-481. 
- Booth, D.T. \& Astill, K. (2001). Incubation temperature, energy expenditure and hatchling size in the green turtle (Chelonia mydas), a species with temperature-sensitive sex determination. Aust. J. Zool. 49, 389-396.

- Broderick, A.C., Godley, B.J. \& Hays, G. (2001). Metabolic heating and the prediction of sex ratios for green turtles (Chelonia mydas). Physiol. Biochem. Zool. 74, 161-170.

- Cornelius, S.E., Alvarado-Ulloa, M., Castro, J.C., Mata de Valle, M. \& Robinson, D.C. (1991). Management of olive ridley sea turtles (Lepidochelys olivacea) nesting at playas Nancite and Ostional, Costa Rica. In Neotropical wildlife use and conservation: 111-135. Robinson, J.G. \& Redford, K.H. (Eds). Chicago: The University of Chicago Press.

- Crouse, D.T. (1999). Population modeling and implications for Caribbean hawksbill sea turtle management. Chelonian Conserv. Biol. 3, 185-188.

- Drake, D.L. \& Spotila, J.R. (2002). Thermal tolerances and the timing of sea turtle hatchling emergence. J. Therm. Biol. 27, 71-81.

- Eckert, K.L. \& Eckert, S.A. (1990). Embryo mortality and hatch success in in situ and translocated leatherback sea turtle Dermochelys coriacea eggs. Biol. Conserv. 53, 37-46.

- Eckrich, C.E. \& Owens, D.W. (1995). Solitary versus arribada nesting in the olive ridley sea turtles (Lepidochelys olivacea): a test of the predation-satiation hypothesis. Herpetologica 51, 349-354.

- Etchberger, C.R., Ewert, M.A., Phillips, J.B., Nelson, C.E. \& Prange, H.D. (1992). Physiological responses to carbon dioxide in embryonic red-eared slider turtles, Trachemys scripta. J. Exp. Zool. 264, 1-10.

- García, A., Ceballos, G. \& Adaya, R. (2003). Intensive beach management as an improved sea turtle conservation strategy in Mexico. Biol. Conserv. 111, 253-261.

- Hewavisenthi, S. \& Parmenter, C.J. (2001). Influence of incubation environment on the development of the flatback turtle (Natator depressus). Copeia 2001, 668-682.

- Hewavisenthi, S. \& Parmenter, C.J. (2002). Incubation environment and nest success of the flatback turtle (Natator depressus) from a natural nesting beach. Copeia 2002, 302-312.

- Hughes, D.A. \& Richard, J.D. (1974). The nesting of the pacific ridley turtle Lepidochelys olivacea on Playa Nancite, Costa Rica. Mar. Biol. 24, 97-107.

- Kam, Y.-C. (1993a). Physiological effects of hypoxia on metabolism and growth of turtle embryos. Resp. Physiol. 92, 127-138.

- Kam, Y.-C. (1993b). Critical oxygen tension of reptilian embryos. Comp. Biochem. Physiol. 105A, 777-783.

- Littell, R.C., Millinken, G.A., Stroup, W.W. \& Wolfinger, R.D. (1996). SAS systems for mixed models. Cary, NC: SAS Institute.

- Maloney, J.E., Darian-Smith, C., Takahashi, Y. \& Limpus, C.J. (1990). The environment for development of the embryonic loggerhead turtle (Caretta caretta) in Queensland. Copeia 1990, 378-387.

- Miller, J.D. (1985). Embryology of marine turtles. In Biology of the reptilia, Vol. 14: 269-328. Gans, C., Billett, F. \& Maderson, P.F.A. (Eds). New York: Wiley.

- Miller, J.D. (1999). Determining clutch size and hatching success. In Research and management techniques for the conservation of sea turtles. Eckert, K.L., Bjorndal, K.A., Abreu-Grobois, F.A. \& Donnelly, M. (Eds). Washington DC: IUCN/SSC Marine Turtle Specialist Group Publication 4.

- Mo, C.L., Salas, I. \& Caballero, M. (1990). Are fungi and bacteria responsible for olive ridley's egg loss? In Proceedings of the 10th annual workshop in sea turtle biology and conservation. NOAA technical memorandum NMFS-SEFC 278: 249-251. Richardson, T.H. \& Richardson, J.I. (Eds). Miami.

- Morreale, S.J., Ruiz, G.J., Spotila, J.R. \& Standora, E.A. (1982). Temperature-dependent sex determination: current practices threaten conservation of sea turtles. Science 216, 12451247.

- Mortimer, J.A. (1990). The influence of beach sand characteristics on the nesting behavior and clutch survival of green turtles (Chelonia mydas). Copeia 1990, 802-817. 
- Packard, G.C. \& Packard, M.J. (1988). The physiological ecology of reptilian eggs and embryos. In Biology of the reptilia, Vol. 16: 523-605. Gans, C. \& Huey, R.B. (Eds). New York: Liss.

- Packard, G.C., Tracy, C.R. \& Roth, J.J. (1977). The physiological ecology of reptilian eggs and embryos, and the evolution of viviparity within the class Reptilia. Biol. Rev. 52, 71-105.

- Phillott, A.D. \& Parmenter, C.J. (2001a). The distribution of failed eggs and the appearance of fungi in artificial nests of green (Chelonia mydas) and loggerhead (Caretta caretta) sea turtles. Aust. J. Zool. 49, 713-718.

- Phillott, A.D. \& Parmenter, C.J. (2001b). Influence of diminished respiratory surface area on survival of sea turtle embryos. J. Exp. Zool. 289, 317-321.

- Plotkin, P.T., Rostal, D.C., Byles, R.A. \& Owens, D.W. (1997). Reproductive and developmental synchrony in female Lepidochelys olivacea. J. Herpetol. 31, 17-22.

- Pritchard, P.C.H. \& Plotkin, P.T. (1995). Olive ridley sea turtle. In Status reviews of sea turtles listed under the Endangered Species Act of 1973: 123-139. National Marine Fisheries Service and U.S. Fish and Wildlife Service (Eds). Silver Spring, MD: National Marine Fisheries Service.

- Ralph, C.R., Reina, R.D., Wallace, B.P., Sotherland, P.R., Spotila, J.R. \& Paladino, F.V. (2005). Effect of egg location and respiratory gas concentrations on developmental success in nests of the leatherback turtle, Dermochelys coriacea. Aust. J. Zool. 53, 289-294.

- Reynolds, D.P. (2000). Hatching success and the nest environment of natural and hatchery nests of the Leatherback turtle (Dermochelys coriacea) at Playa Grande, Costa Rica, 19981999. MS thesis, Drexel University, Philadelphia.

- Spotila, J.R., Reina, R.D., Steyemark, A.C., Plotkin, P.T. \& Paladino, F.V. (2000). Pacific leatherback turtles face extinction. Nature 405, 529-530.

- Standora, E.A. \& Spotila, J.R. (1985). Temperature sex determination in sea turtles. Copeia 1985, 711-722.

- Tripathy, B., Shanker, K. \& Choudhury, B.C. (2003). Important nesting habitats of olive ridley turtles (Lepidochelys olivacea) along the Andhra Pradesh coast of eastern India. Oryx 37, 454-463.

- Valverde, R.A., Cornelius, S.E. \& Mo, C.L. (1998). Decline of the olive ridley sea turtle (Lepidochelys olivacea) nesting assemblage at Nancite beach, Santa Rosa National Park, Costa Rica. Chelonian Conserv. Biol. 3, 58-63.

- Wallace, B.P., Sotherland, P.R., Spotila, J.R., Reina, R.D., Franks, B.F. \& Paladino, F.V. (2004). Biotic and abiotic factors affect the nest environment of embryonic leatherback turtles, Dermochelys coriacea. Physiol. Biochem. Zool. 77, 423-432.

- Wyneken, J., Burke, T.J., Salmon, M. \& Pedersen, D.K. (1988). Egg failure in natural and relocated sea turtle nests. J. Herpetol. 22, 88-96.

- Yntema, C.L. \& Mrosovsky, N. (1980). Sexual differentiation in hatchling loggerheads (Caretta caretta) incubated at different controlled temperatures. Herpetologica 36, 33-36. 


\section{Figures}

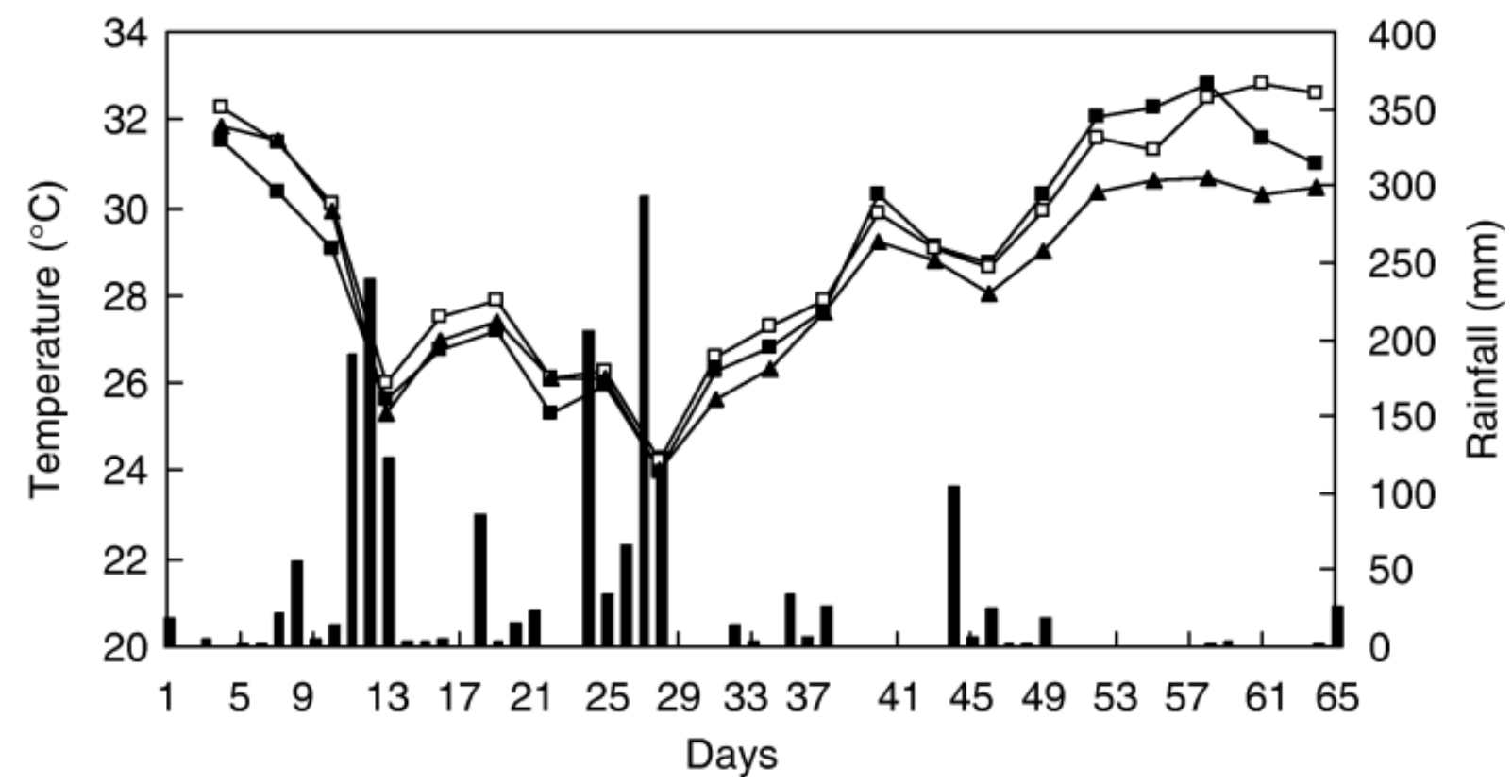

Figure 1. Mean hatchery and beach nest temperatures $\left({ }^{\circ} \mathrm{C}\right)$ during the incubation period of olive ridley turtle Lepidochelys olivacea eggs deposited at Nancite beach (Costa Rica) during the arribada of September 1999. Temperatures of $(\cdot)$ hatchery nests, $(\square)$ in situ nests and $(\mathbf{\Delta})$ sand at nest depth (average of hatchery and beach sites) were monitored every 3 days at 09:00 h. Bars represent rainfall throughout the incubation period. 

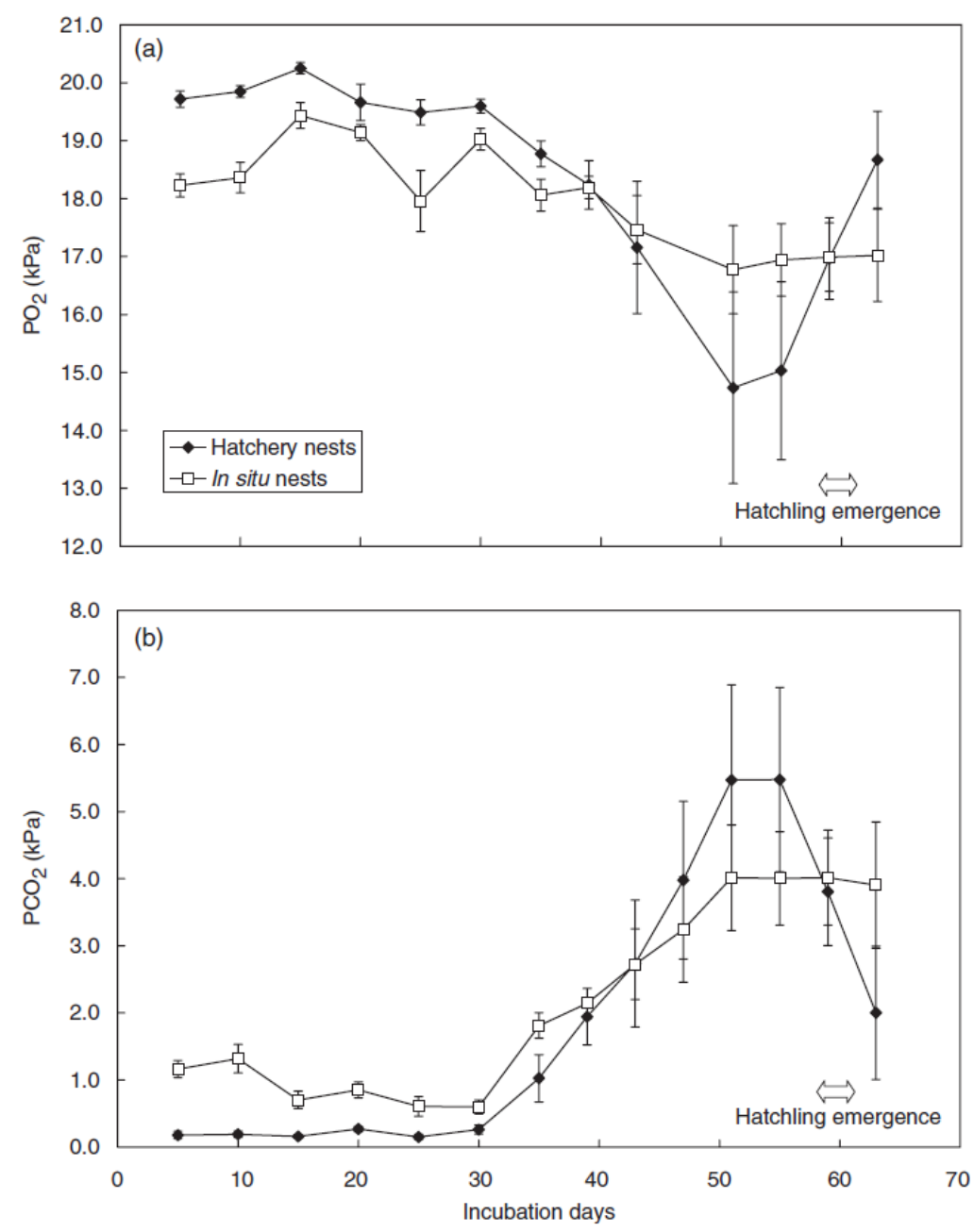

Figure 2. Mean oxygen $\left(\mathrm{a}, \mathrm{PO}_{2}\right)$ and carbon dioxide $\left(\mathrm{b}, \mathrm{PCO}_{2}\right)$ partial pressures of hatchery and in situ nests during the incubation of eggs deposited by olive ridley turtles Lepidochelys olivacea at Nancite beach, Costa Rica (1999). Values are means \pm sd. 
Tables

\begin{tabular}{|c|c|c|c|c|}
\hline & Hatchery $(n=14)$ & In situ $(n=4)$ & $\boldsymbol{U}$ & $\boldsymbol{P}$ \\
\hline Number of eggs & $101.7 \pm 19.3$ & $95.0 \pm 11.0$ & 17.5 & 0.26 \\
\hline Incubation period (days) & $60.4 \pm 1.3$ & $60.0 \pm 1.4$ & 10.5 & 0.58 \\
\hline Hatching success (\%) & $83.1 \pm 14.6$ & $21.6 \pm 17.4$ & 0.0 & 0.003 \\
\hline \multicolumn{5}{|l|}{ Hatchlings } \\
\hline Emerged & $82 \pm 23$ & $13 \pm 18$ & 0.0 & 0.003 \\
\hline Alive & $1 \pm 1$ & $2 \pm 3$ & 25.0 & 0.75 \\
\hline Dead & $1 \pm 1$ & $1 \pm 1$ & 25.0 & 0.75 \\
\hline \multicolumn{5}{|l|}{ Embryos } \\
\hline Late & $11 \pm 12$ & $23 \pm 22$ & 20.0 & 0.39 \\
\hline Middle & $0 \pm 1$ & $4 \pm 4$ & 15.0 & 0.03 \\
\hline Early & $5 \pm 6$ & $49 \pm 32$ & 1.0 & 0.004 \\
\hline
\end{tabular}

For hatchlings (number of individuals): emerged, emerged naturally at the sand surface; alive and dead, alive and dead in the nest cavity. For embryos: late, pigmented and fully formed, yolk < embryo volume; middle, presence of pigmentation, yolk > embryo volume; early, small unpigmented embryo and/or blood formations and embryonic membranes. All values are means of nest values \pm sd. Hatchery and in situ nest groups were compared using non-parametric Mann-Whitney $U$-tests. 


\begin{tabular}{|c|c|c|}
\hline & Hatchery & Beach \\
\hline \multicolumn{3}{|l|}{$T_{\mathrm{a}}\left({ }^{\circ} \mathrm{C}\right)$} \\
\hline$n$ & 20 & 20 \\
\hline Mean $\pm s d$ & $28.6 \pm 3.1$ & $28.5 \pm 2.9$ \\
\hline Median & 29.6 & 28.9 \\
\hline Maximum & 33.2 & 32.7 \\
\hline Minimum & 23.8 & 23.9 \\
\hline \multicolumn{3}{|l|}{$T_{\mathrm{s}}\left({ }^{\circ} \mathrm{C}\right)$} \\
\hline $\begin{array}{ll}n \\
\end{array}$ & 20 & 20 \\
\hline Mean \pm sd & $28.3 \pm 2.2$ & $28.8 \pm 2.5$ \\
\hline Median & 28.6 & 29.4 \\
\hline Maximum & 31.7 & 32.1 \\
\hline Minimum & 24.0 & 24.0 \\
\hline \multicolumn{3}{|c|}{ Sand moisture $(\mathrm{kPa})$} \\
\hline$n$ & 17 & 17 \\
\hline Mean \pm sd & $-9.8 \pm 2.8$ & $-8.2 \pm 2.3$ \\
\hline Median & -9.5 & -9.0 \\
\hline Minimum & -13.5 & -13.0 \\
\hline Maximum & $\mid-5.0$ & -4.5 \\
\hline
\end{tabular}

Data were collected at 09:30 $\mathrm{h}$ every three 3 days during the incubation of study nests (c. 60 days). $n$, number of observations.

Table 3. Summary of results of the repeated measures ANOVA investigating the effect of Location (hatchery vs. beach), Day (sampling date) and the interaction between these two variables (Location $\times$ Day) on temperature, oxygen $\left(\mathrm{PO}_{2}\right)$ and carbon dioxide $\left(\mathrm{PCO}_{2}\right)$ partial pressures at the center of 20 hatchery and 15 in situ egg-clutches during the first half of the incubation period

\begin{tabular}{|c|c|c|c|c|c|c|c|c|c|}
\hline \multirow{2}{*}{ Source } & \multicolumn{3}{|c|}{ Temperature } & \multicolumn{3}{|c|}{$\mathrm{PO}_{2}$} & \multicolumn{3}{|c|}{$\mathrm{PCO}_{2}$} \\
\hline & d.f. & $F$ & $P$ & d.f. & $F$ & $P$ & d.f. & $F$ & $P$ \\
\hline Location & 1,288 & 79.74 & $<0.001$ & 1,175 & 173.91 & $<0.001$ & 1,176 & 173.9 & $<0.001$ \\
\hline Day & 9,288 & 510.76 & $<0.001$ & 5,175 & 15.14 & $<0.001$ & 5,176 & 6.17 & $<0.001$ \\
\hline Location $\times$ Day & 9,288 & 1.95 & 0.05 & 5,175 & 6.11 & $<0.001$ & 5,176 & 6.17 & $<0.001$ \\
\hline
\end{tabular}




\begin{tabular}{|c|c|c|c|c|c|c|}
\hline \multirow{2}{*}{ Variable/clutch characteristic } & \multicolumn{3}{|c|}{ First half incubation } & \multicolumn{3}{|c|}{ Full incubation period } \\
\hline & $r$ & $n$ & $P$ & $r$ & $n$ & $P$ \\
\hline \multicolumn{7}{|l|}{ Temperature } \\
\hline \multicolumn{7}{|l|}{ Clutch size } \\
\hline Mean & 0.20 & 20 & 0.40 & 0.32 & 10 & 0.36 \\
\hline Maximum & 0.28 & 20 & 0.23 & 0.52 & 10 & 0.12 \\
\hline Minimum & 0.20 & 20 & 0.39 & & & \\
\hline \multicolumn{7}{|l|}{ Metabolizing embryos } \\
\hline Mean & -0.03 & 10 & 0.94 & 0.41 & 10 & 0.24 \\
\hline Maximum & 0.32 & 10 & 0.36 & 0.62 & 10 & 0.06 \\
\hline Minimum & 0.15 & 10 & 0.67 & & & \\
\hline \multicolumn{7}{|l|}{ Incubation period } \\
\hline Mean & 0.36 & 10 & 0.31 & -0.36 & 10 & 0.31 \\
\hline Maximum & -0.01 & 10 & 0.98 & -0.54 & 10 & 0.11 \\
\hline Minimum & 0.12 & 10 & 0.74 & & & \\
\hline \multicolumn{7}{|l|}{$\mathrm{PO}_{2}$} \\
\hline \multicolumn{7}{|l|}{ Clutch size } \\
\hline Mean & -0.13 & 20 & 0.57 & -0.58 & 10 & 0.08 \\
\hline Maximum & -0.20 & 20 & 0.38 & & & \\
\hline Minimum & -0.07 & 20 & 0.76 & -0.73 & 10 & 0.02 \\
\hline \multicolumn{7}{|l|}{ Metabolizing embryos } \\
\hline Mean & -0.59 & 10 & 0.07 & -0.62 & 10 & 0.06 \\
\hline Maximum & -0.46 & 10 & 0.18 & & & \\
\hline Minimum & -0.11 & 10 & 0.77 & -0.72 & 10 & 0.02 \\
\hline \multicolumn{7}{|l|}{ Incubation period } \\
\hline Mean & 0.13 & 10 & 0.72 & 0.27 & 10 & 0.46 \\
\hline Maximum & 0.14 & 10 & 0.69 & & & \\
\hline Minimum & -0.27 & 10 & 0.44 & 0.13 & 10 & 0.71 \\
\hline \multicolumn{7}{|l|}{$\overline{P \mathrm{PCO}_{2}}$} \\
\hline \multicolumn{7}{|l|}{ Clutch size } \\
\hline Mean & 0.44 & 20 & 0.05 & 0.59 & 10 & 0.07 \\
\hline Maximum & 0.55 & 20 & 0.01 & 0.62 & 10 & 0.06 \\
\hline Minimum & 0.42 & 20 & 0.07 & & & \\
\hline \multicolumn{7}{|l|}{ Metabolizing embryos } \\
\hline Mean & 0.61 & 10 & 0.06 & 0.66 & 10 & 0.04 \\
\hline Maximum & 0.60 & 10 & 0.07 & 0.62 & 10 & 0.06 \\
\hline Minimum & 0.64 & 10 & 0.04 & & & \\
\hline \multicolumn{7}{|l|}{ Incubation period } \\
\hline Mean & -0.54 & 10 & 0.11 & -0.27 & 10 & 0.46 \\
\hline Maximum & -0.50 & 10 & 0.14 & -0.02 & 10 & 0.94 \\
\hline Minimum & -0.56 & 10 & 0.09 & & & \\
\hline
\end{tabular}

$r$, Spearman's rank correlation coefficient; $n$, sample size. Rows with no values imply that the variable only occurred during the first half of the incubation period. Units in bold indicate significant correlations. 